\title{
Intragastric self-administration of alcohol by rats: A dose-effect comparison
}

\author{
TOREEN E. WERNER, STANLEY G. SMITH, and W. MARVIN DAVIS \\ Department of Pharmacology, University of Mississippi, University, Mississippi 38677
}

\begin{abstract}
Rats were implanted with a trans-esophageal intragastric cannula and allowed access to saline and three different dosages of ethyl alcohol (EA). Dosages of EA employed were 25, 50, and $100 \mathrm{mg} / \mathrm{kg} /$ infusion. All subjects readily self-administered the EA at all dosages in a doserelated fashion. The greatest number of infusions was taken by the lowest dosage group, while the least number of infusions was taken by the highest dosage group. For the amount selfadministered, the reverse order was observed; rats in the highest dosage group had the highest intake of drug, while those in the lowest dosage group self-administered the least amount.
\end{abstract}

The intragastric (IG) drug self-administration methodology has provided a much needed alternative to oral "drinking" technique. The IG cannula bypasses the orosensory receptors and delivers a drug solution directly to the stomach. In this manner, drugs such as alcohol, which are not readily consumed by lower animals, can be more easily studied. To date, most published reports are demonstrations that some orally aversive compounds are readily self-administered by this method (Altschuler, Weaver, \& Phillips, 1975; Gotestam, 1973; MarfaingJollat, Pruvost and Le Magnen, 1974; Smith, Werner, \& Davis, 1975). The only study to provide additional information was one examining the lower end dose-effect of alcohol (Smith, Werner, \& Davis, 1976a). These data indicated that increases in dose, to $3.0 \mathrm{mg} / \mathrm{kg}$, resulted in increases in numbers of infusions and amount selfadministered. Theoretically, the numbers of infusions should peak and then decrease with increases in unit dose. Therefore, to provide data on the upper range of intragastric alcohol's dose-response effects, the following research was instituted.

\section{METHOD}

\section{Subjects}

The subjects were adult male rats of Sprague-Dawley descent. Twenty rats were employed for this experiment, with five animals per group. All animals were drug naive at the beginning of the experiment. Food and water were available ad lib in both the home cage and experimental chamber throughout the experimenter.

\section{Apparatus}

The rats were implanted with chronic esophageal intragastric cannulas, which passed from the esophagus subcutaneously to an exit on the upper back (for details, see Smith, Werner, \& Davis,

This research was supported by Research Grant AA 01217-01 from NIAAA, and in part by the Research Institute of Pharmaceutical Sciences, School of Pharmacy, University of Mississippi. Reprints may be obtained from any author at the Department of Pharmacology, University of Mississippi, University, Mississippi 38677.
1975). At the back, the catheter was attached to an external harness. The harness was then connected to a length of springwrapped plastic tubing which joined a leak-proof swivel at the top center of the chamber. The opposite end of the swivel was connected by vinyl tubing to an infusion pump which delivered $.092 \mathrm{ml}$ of $.9 \%$ saline or EA solution in $1 \mathrm{sec}$ each time it was activated. The experimental chambers, clear plastic cylinders $24 \mathrm{~cm}$ high and $25 \mathrm{~cm}$ in diameter, contained a response lever, food, and water. Each chamber was lighted and enclosed in a ventilated sound-attenuated compartment. Leverpresses were registered on electromechanical counters, and all programming was accomplished via solid state electronic circuitry.

\section{Procedure}

The subjects were placed in the test chambers, attached to the injection system and allowed a 1-h period for adaptation to the chambers. Following adaptation, the operant level of leverpressing was determined for a 10-h period, during which each response was followed by an intragastric infusion of saline. Superimposed on the infusion interval was a buzzer presentation of equal duration. On each of the subsequent 5 days, a 10-h acquisition period was run, with all conditions identical to those of the first day except that subjects were allowed access to 0 (saline), 25,50 , or $100 \mathrm{mg} / \mathrm{kg} /$ infusion of ethyl alcohol. Each dosage group consisted of five individual animals. Statistical comparisons between groups refer to data on Day 5 .

\section{RESULTS}

Figure 1 shows the mean number of infusions taken by different treatment groups. It can be seen that the 0 (or saline) dose group did not maintain selfadministration behavior. Note also that the greatest number of infusions was taken by the lowest treatment group (25), followed in decreasing order by the 50 - and $100-\mathrm{mg} / \mathrm{kg} /$ infusion groups. The number of infusions for all doses of EA, 25,50 , and $100 \mathrm{mg} / \mathrm{kg} /$ infusion, significantly exceeded the infusions of saline $(p<.05)$. However, the number of infusions did not differ significantly among the three EA groups $(\mathrm{p}>.05)$.

Figure 2 shows the amount of drug self-administered for all groups. The greatest amount of EA was taken by the highest dosage group ( $100 \mathrm{mg} / \mathrm{kg} /$ infusion $)$, followed in decreasing order by the 50-, 25-, and $0-\mathrm{mg} / \mathrm{kg} /$ infusion 


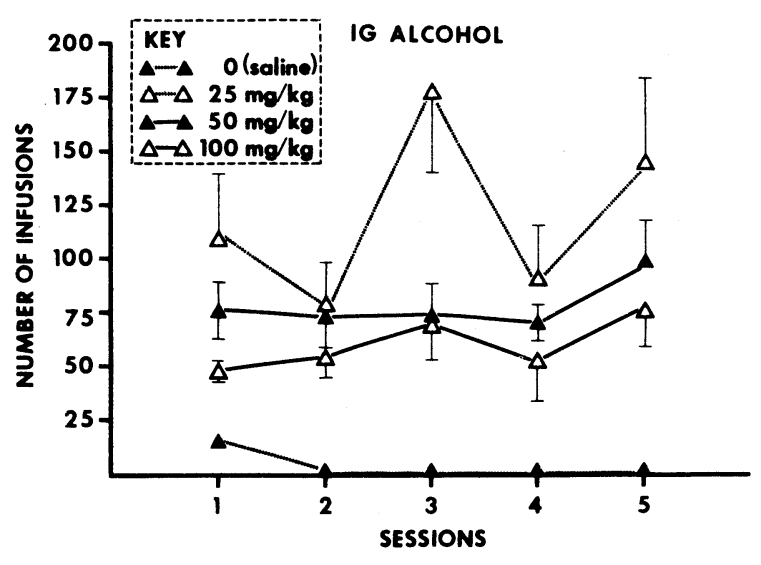

Figure 1. Mean number of infusions of intragastric alcohol taken at different unit doses.

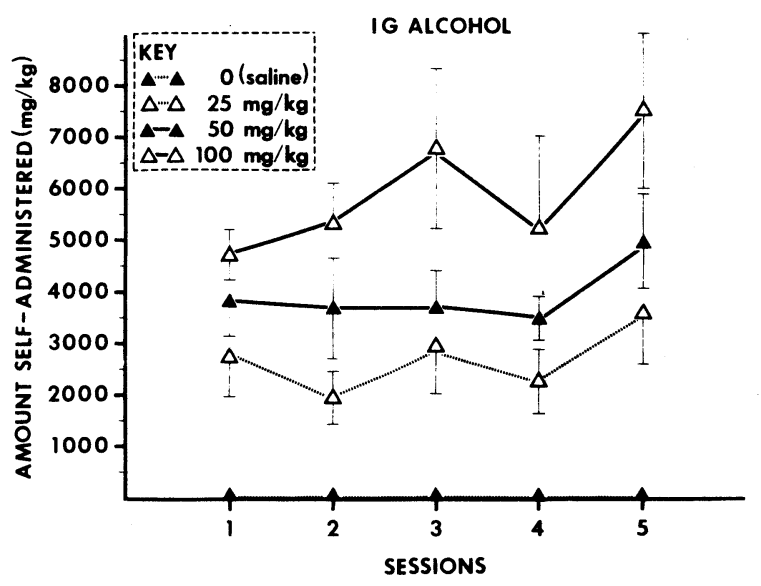

Figure 2. Mean amount (mg/ $/ \mathrm{kg})$ of intragastric alcohol selfadministered at different unit doses.

groups. Statistical analysis shows that all EA groups differed significantly. Intake by the $100-\mathrm{mg} / \mathrm{kg}$ group exceeded that of both the $50-\mathrm{mg} / \mathrm{kg}(\mathrm{p}<.05)$ and $25-\mathrm{mg} / \mathrm{kg}(\mathrm{p}<.01)$ groups, but the later two groups did not differ significantly from one another.

\section{DISCUSSION}

Previous alcohol self-administration research with the intragastric route has indicated that increases in unit dose up to $3.0 \mathrm{mg} / \mathrm{kg} /$ infusion, highest dose studied, produce increases in number of infusions and amount self-administered (Smith et al., 1976a). The above research examined only lower range dose effects. The present research was an attempt to provide data on upper range dose effects. These data indicated that increases in the dose of alcohol to $25 \mathrm{mg} / \mathrm{kg} /$ infusions produced the largest number of infusions taken, while further increases in dose resulted in a dose-related decline. The amount self-administered increased with increase in unit dose. Results for numbers of infusions and amount self-administered are similar to those reported for morphine via the same route (Smith, Werner, \& Davis, 1976b).

With morphine and alcohol, increases in unit dose at the lower range produced increases in number of infusions taken and amount self-administered. Increases in unit dose at the upper range produced a decrease in number of infusions taken with an increase in amount self-administered. If potency comparisons were made between morphine and alcohol, the highest dose of morphine studied, $10 \mathrm{mg} / \mathrm{kg} /$ infusion, resulted in numbers of infusions very similar to those obtained for the highest alcohol dose studied, $100 \mathrm{mg} / \mathrm{kg} /$ infusion. While species, sex, experimental environments, and methods were identical for both studies, the time factor allows possible occurrence of historical incidence variables, i.e., temperature, etc., and exact quantification comparisons are not possible. Yet it is clear that upper dose morphine effects are far more potent than alcohol in a selfadministration paradigm.

\section{REFERENCE NOTE}

1. Yanagita, T., Ando, K., Takahashi, S., \& Ishida, K. Self-administration of barbiturates, alcohol (intragastric), and CNS stimulants (intravenous) in monkeys. Paper presented to the Committee on Problems of Drug Dependence, Palo Alto, California. February 1969.

\section{REFERENCES}

Altschuler, H., Weaver, S., \& Phillips, P. Intragastric selfadministration of psychoactive drugs by the rhesus monkey. Life Sciences, 1975, 17, 883-890.

GotestaM, K. G. Intragastric self-administration of medazepam in rats. Psychopharmacologia, 1973, 38, 87-94.

Marfaing-Jollat, P., Pruvost, M., \& Le Magnen, J. La consommation de ethanol par auto-administration intragastrique chez le rat. Journal de Physiologie (Paris), 1974, 68, 81-95.

Smith, S. G., Werner, T. E., \& Davis, W. M. Technique for intragastric delivery of solutions: Application for selfadministration of morphine and alcohol by rats. Physiological Psychology, 1975, 3, 220-224.

Smith, S. G., Werner, T. E., \& Davis, W. M. Comparison between intravenous and intragastric alcohol self-administration. Physiological Psychology, 1976, 4, 91-93. (a)

Smith, S. G., Werner, T. E., \& Davis, W. M. Effect of unit dose and route of administration on self-administration of morphine. Psychopharmacology, 1976, 50, 103-105. (b)

(Received for publication August 22, 1977; accepted September 2, 1977.) 